\title{
Poor CALGB Criteria
}

National Cancer Institute

\section{Source}

National Cancer Institute. Poor CALGB Criteria. NCI Thesaurus. Code C160759.

A rating for AML by CALGB which indicates the outlook on the patient recovery can be considered poor. 